\title{
Etiology, Presentation and Management of Liver Abscesses at the Children's Hospital Lahore
}

\author{
HUMA ARSHAD CHEEMA, ${ }^{1}$ ANJUM SAEED ${ }^{2}$ \\ Address For Correspondence: Dr. Huma Arshad Cheema Professor and Head of the Department, Division of Pediatric \\ Gastroenterology-Hepatology, The Children's Hospital and the Institute of Child Health, Lahore
}

Background: Liver abscess is a common problem among children. The purpose of this study is to describe the etiology, different management strategies and outcome of children with liver abscess in Children's Hospital Lahore.

Patients and Methods: This study included 38 children with liver abscess seen during two-year period, from September 2004 to September 2006 at the Children's Hospital and Institute of Child Health, Lahore. Diagnosis was made on history, examination and investigations. Ultrasound and CT scan were the main diagnostic tools.

Results: Out of 38 patients, 33 children underwent aspiration and remaining 5 were managed conservatively. Eight aspirates yielded positive culture for various organisms. Three patients were positive for E.Coli, 2 for Staph Aureus, and 1 each case of Klebsiella and Pseudomonas. One patient had multiple micro-abscesses and was also positive for typhidot IgM. Another patient was positive for acid fast mycobacterium tuberculosis. All patients recovered from their abscesses. There was no mortality reported.

Conclusions: In our pediatric population, liver abscess are mostly caused by pyogenic organisms. Amebic etiology was not proven in any case. Majority of liver abscesses can be satisfactorily treated by aspiration and /or percutaneous image guided drainage with satisfactory outcome.

Key Words: Liver abscess, children.

\section{Introduction}

Hepatic abscess is not an uncommon problem in children living in poor hygienic conditions in third world countries. Although the majority of intra-abdominal abscesses are not localized to an organ, the liver is most commonly involved when a visceral abscess occurs. ${ }^{1}$ It could result as a complication of various intra-abdominal infections; by hematogenous spread via portal vein from the gastrointestinal tract; or, may develop after traumatic injury to the liver. The two most common varieties of liver abscess are pyogenic and amebic. $^{2}$ Children presenting with liver abscess have variable clinical features like fever, right upper quadrant pain or the features of associated disease and complications., ${ }^{3,4}$ Ultrasound is the main diagnostic tool and in some cases CT scan may be helpful. ${ }^{5,6}$ Treatment of patients is both medical and drainage of abscess, depending upon the size and location of liver abscess.

The purpose of this study was to describe the etiology, mode of management and outcome of children with liver abscesses.

\section{Patients and Methods}

This is a prospective descriptive study. It includes 38 children with liver abscesses presenting to the Children's Hospital and Institute of Child Health, Lahore during a two-year period from September 2004 to September 2006. Diagnosis was made on history, examination and investigations. Ultrasound and CT scan were the main diagnostic tools (Fig 1 \& 2). A complete blood count, ESR, liver function tests coagu- lation profile and a chest x-ray was also done in all cases. All patients had 3 stool examinations and indirect Haemagglutination test for Entameba histolytica.. Aspirated pus was sent for gram stain and culture. History and physical examination of these children were recorded on pre-designed form. Following management guidelines were followed. If abscess was less than $4 \mathrm{~cm}$ in diameter and was not liquefied on ultrasound, only antibiotics were used. Same size abscess when liquefied was treated by aspiration alone. All abscessses which were liquefied and were more than $4 \mathrm{~cm}$ had image guided insertion of mushroom-tipped catheter for drainage (Fig. 3). This was done under local anesthesia and sedation. Prothrombin and activated partial thromboplastin times were checked before aspiration or drainage. All patients received antibiotics. Aspirate was sent for cytology, culture and sensitivity.

\section{Results}

Thirty eight children were included in this study. Youngest child was 2 years old and oldest was 13.5 years. Thirty three patients were male and 5 were female. History of fever (100\%) was present in all the patients. Second major presentation was abdominal pain (89\%) and vomiting (33\%). Two patients (5.26\%) had jaundice. None of the patients had History of dysentery. On examination Anaemia (97\%) and tender hepatomegaly (72\%) were common findings Only one of the patients had hemoglobin $>9 \mathrm{gm} / \mathrm{dl}$ (Range $4.3-$ 9.6). Respiratory distress was seen in 4 patients (10.5\%) with liver abscess that had infiltrated into the thoracic 

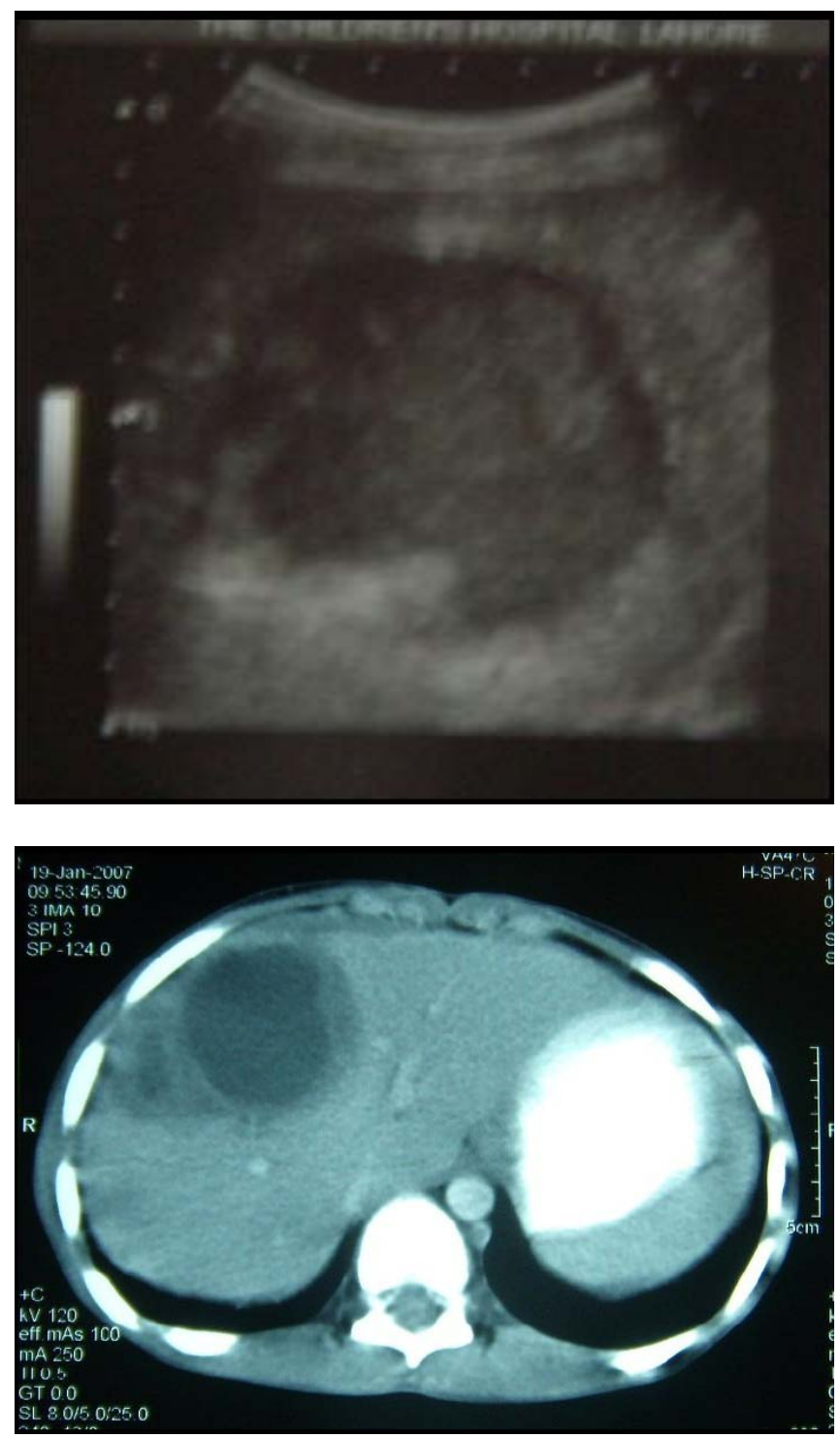

Fig 1 \& 2: Ultrasound (above) and CT scan (below) showing liver abscess.

cavity. Only 2 patients with multiple abscesses had deranged liver function tests with elevated transaminases (97 \& 120 units/dl) and mild hyperbilirubinemia (3.3 mg/dl, \& .7 $\mathrm{mg} / \mathrm{dl}$ ) One of them had salmonella Typhi on blood culture. X-ray abdomen revealed elevation of right hemidiaphragm in 25 cases (65\%). Tests for Entamoeba were negative in all patients. Thirty three of 38 children underwent percutaneous image guided aspiration and drainage Eight aspirates proved culture positive for various organisms Three patients were positive for E.Coli, 2 for Staph Aureus, 1 each for Klebsiella and Pseudomonas, 1 patient had multiple microabscesses and was also positive for typhidot IgM and 1 patient was positive for acid fast mycobacterium tuberculosis. All patients responded to percutaneous drainge and antibiotic therapy. 4 patients also required chest tube insertion as the abscess had ruptured there. Abscess cavity resolved in average
30 days. There was no mortality. No patient had amebiasis as the cause of liver abscess.

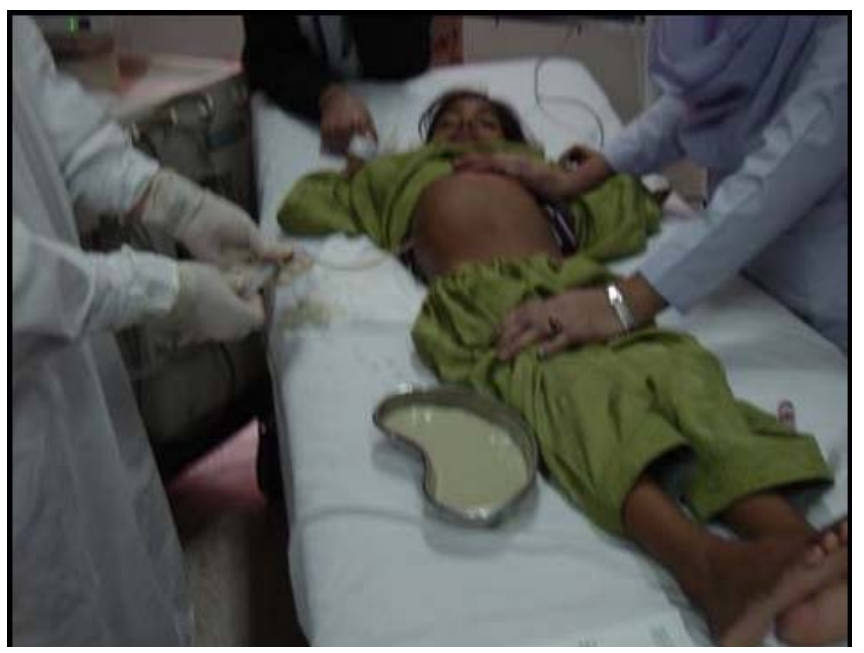

Fig 3: Percutaneous drainage of liver abscess with ultrasound guidance.

\section{Discussion}

Hepatic abscess is not an uncommon problem in children living in poor hygienic conditions. ${ }^{1}$ Fever, right upper quadrant pain and vomiting were common presenting features. In a study done in UK fever is the most common finding at presentation, occurring in approximately 90 percent of patients. ${ }^{3,4}$ The majority of patients (55 to 74 percent) also have abdominal pain and/or tenderness. Ultrasound and CT scan are highly diagnostic for liver abscess. ${ }^{5,6}$.Single abscess in right lobe is more common. ${ }^{7}$ Most patients had low hemoglobin, and high leukocyte count. But in some cases TLC count may be normal depends upon patient's immunological response. ${ }^{8}$ Elevated right dome of diaphragm was common $\mathrm{x}$-rays finding. Contrary to popular belief, most of liver abscesses in children in this third world country are pyogenic and not amebic in origin. Pyogenic liver abscess is more common than amebic in children as compared to adults. ${ }^{2,9}$ In our study most common organism was E.Coli but in other studies klebsilla and staph aureues are commonest organisms and there was not a single case of amebic abscess. ${ }^{10,11}$ Majority of these abscesses could be successfully managed by image guided aspiration / drain insertion with appropriate antibiotics. Open surgical drainage is rarely required Hepatic tubeculous abscess is rare but needs to be considered if patient is not responding to conventional treatment. ${ }^{12,13}$ Conservative management of smaller abscess $(<5 \mathrm{~cm})$ is as effective. Percutaneous needle aspiration under ultrasound guidance was found best for non-complicated larger abscess $(>5 \mathrm{~cm})$ as also proved by other studies. ${ }^{14}$

\section{Conclusions}

The most common cause of liver abscess in our study was pyogenic and among pyogenic E.coli was the commonest 
organism but hepatic tuberculous abscess although rare should be considered if patient does not respond to conventional treatment. With good medical measures, safe and aseptic drainage of liver abscess complications can be reduced.

\section{References}

1. Altemeier, WA, Culbertson, WR, Fullen, WD, Shook, CD. Intra-abdominal abscesses. Am J Surg 1973; 125: 70.

2. Huang, C-J, Pitt, HA, Lipsett, PA, et al. Pyogenic heaptic abscess: Changing trends over 42 years. Ann Surg 1996; 223: 600.

3. Noons, Milar MW: Liver abscess in childhood, Pediatr Surg. int. 1988; 3: 27-32.

4. Ranairez CP, Hernandex H Jauri H Ameobic hepatic abscess in children. J. Pediatr. Surg. 1995; 30: -662-4.

5. Zaleznik, DF, Kasper, DL. Intra-abdominal abscesses. In: Gastrointestinal Infections: Diagnosis and Management, Lamont, JT (Ed), Marcel Dekker, New York 1997. p. 397.

6. Gulshan Au, Qayyum M.A, Ali Mr. An experience with amoebic liver abscess at PMCH Nawab Shah Medical Channel, 1999; 2: 1-14.

7. Memon A.M., Memon J.M.: "Liver abscess in children J. Surg. Pakistan (International) 1997; 2: -13-5.
8. Mustafa A, Safdar AM: Liver abscess presentations and management mother and child 1997; 35: 67-69.

9. Yu, SC, Ho, SS, Lau, WY, et al. Treatment of pyogenic liver abscess: prospective randomized comparison of catheter drainage and needle aspiration. Hepatology 2004; 39: 932.

10. Chuang, YP, Fang, CT, Lai, SY, et al. Genetic determinants of capsular serotype K1 of Klebsiella pneumoniae causing primary pyogenic liver abscess. J Infect Dis 2006; 193: 645.

11. Yu, WL, Ko, WC, Cheng, KC, et al. Association between rmpA and magA genes and clinical syndromes caused by Klebsiella pneumoniae in Taiwan. Clin Infect Dis 2006; 42: 1351.

12. Caliskan, Y, Demirturk, M, Cagatay, AA,. Isolated hepatic tuberculous abscess in a renal transplant recipient. Transplant Proc 2006; 38: 1341.

13. Koksal, D, Koksal, AS, Koklu, S, Primary tuberculous liver abscess: A case report and review of the literature. South Med J 2006; 99: 393.

14. Samo MJ, Ahmed M Aspiration of liver abscess. Pak J. Med Sciences; 1997; 13: 389-392.

15. Koksal, D, Koksal, AS, Koklu, S, Primary tuberculous liver abscess: A case report and review of the literature. South Med J 2006; 99: 393. 